\title{
FAILURE PROPERTIES OF PASSIVE HUMAN AORTIC TISSUE. II-BIAXIAL TENSION TESTS
}

\author{
Dinesh MOHAN* \\ Centre for Biomedical Engineering, Indian Institute of Technology, New Delhi 110016, India
}

and

JOHN W. MELVIN

Biomechanics Department, Highway Safety Research Institute, The University of Michigan, Ann Arbor, MI 48109 , U.S.A.

\begin{abstract}
Descending mid-thoracic aortas were obtained from 16 autopsies and biaxial inflation tests performed on the tissue at dynamic $\left(\sim 20 \mathrm{~s}^{-1}\right)$ and quasi-static $\left(\sim 0.01 \mathrm{~s}^{-1}\right)$ strain rates. A bubble inflation technique was developed for this purpose. Extension histories of the specimens were recorded photographically and values of ultimate stresses and extension ratios in biaxial stretch have been calculated. Under conditions of uniform biaxial stretch the tissue consistently failed in a direction perpendicular to the long axis of the aorta and pressure values at failure were greater by a factor of two in the dynamic tests than those in the quasi-static tests.
\end{abstract}

\section{INTRODUCTION}

Uniaxial properties of biological tissues are not sufficient for the purposes of characterizing their mechanical behavior. Such tissues generally exhibit markedly non-linear behavior for finite deformations and are viscoelastic. At the gross level some tissues may be effectively homogenous though they may have anisotropic properties. Most of the experimental work on aortic tissue has consisted of uniaxial extension tests on strips and tubular inflation tests of the whole aorta. Most of these tests were done at quasi-static loading rates and in many cases the stress-strain behavior was not documented. The main emphasis in the study reported here was on impact type high strain rate $\left(\sim 20 \mathrm{~s}^{-1}\right)$ behavior and all tests were performed with the intention of obtaining failure properties of the aortic tissue in biaxial tension.

There has been a long term interest in the mechanics of aortic rupture. Rindfleisch (1873) attributed it to sudden longitudinal stretching of the vessel. Oppenheim (1918) investigated the effect of internal pressure on arteries and reported that normal arteries burst at pressures well over $200 \mathrm{~mm} \mathrm{Hg}$. Tannenbaum and Ferguson (1948) were also of the opinion that a rise in blood pressure plays an important role in aortic rupture, but could not explain ruptures caused by flying pieces of wood and stone.

Letterer (1924) put forward the idea that downward acceleration of the heart causes the ruptures in the ascending aorta, while Sheman (1929) thought the

Received for publication 22 June 1982

* This work was completed while the senior author was at the Highway Safety Research Institute, The University of Michigan, Ann Arbor. Michigan. 'hinge' effect at the isthmus to be the cause for the injury of the descending aorta. Cammack (1959) proposed that an anterior-posterior blow on the chest would cause dislocation of the heart downward and to the left, thus causing torsion in the aorta. This has been supported by Roberts' (1967) study. Lundewall (1964) has also suggested the water hammer effect as a possible cause of rupture. There is no accurate experimental evidence to validate the theories regarding movements of the heart and aorta. It is only very recently that Shatsky et al. (1974) reported their success with high speed X-ray cinematography of anterior chest impacts on five rhesus monkeys (Macacca mulatta). They report distortion of the aortic arch and trapping and occlusion of the descending aorta between the posterior ventricular wall and vertebral bodies. Kroell et al. (1974) impacted human cadaver chests with a pressurized vascular system and measured aortic arch pressures. They recorded pressures as high as $3.7 \times 10^{5} \mathrm{~N} / \mathrm{m}^{2}$, and the two aortic ruptures that were produced were at recorded pressures of over $2.1 \times 10^{5} \mathrm{~N} / \mathrm{m}^{2}$ at the aortic arch. A theoretical analysis of wall stress in curved aortas in blunt chest trauma has been done by Ray et al. (1975) and it is predicted by their model that if the aorta is occluded during impact a reflected pulse wave may travel upstream and thus amplify the pressures considerably.

The bursting pressures of tubular aortas were recorded by, among others, Roy (1880), Collins and $\mathrm{Hu}(1972)$ and Yamada (1970). It is very difficult to get realistic stress and strain values from tubular tests because of very complicated boundary conditions in the short section involved. The problems include the tapering of the aorta, clamping of the specimen, and 
the barrelling effect of inflation. Little of the data in the studies mentioned above is in the high strain range and virtually no accurate stress-strain data exist for the ultimate mechanical properties of the tissue.

Attempts to obtain biaxial properties have been made on tubular specimens of the aorta. Cheung and Hsiao (1972) considered radial deformation only while Kivity and Collins (1974) developed an equation for axial response. Because of the experimental and analytical difficulties inherent in the problem true biplanar response properties of aortic tissue are still not available.

In this study, descending mid-thoracic aortic specimens were obtained from 16 autopsies and biaxial inflation tests performed on the tissue at dynamic $\left(\sim 20 \mathrm{~s}^{-1}\right)$ and quasi-static $\left(\sim 0.01 \mathrm{~s}^{-1}\right)$ strain rates. A bubble inflation technique was developed for this purpose and the test methods are described below.

\section{MATERIALS AND METHODS}

\section{Tissue sources, storage and specimen preparation}

Fresh specimens of human mid-thoracic aortas were obtained from 16 autopsies at The University of Michigan Hospital and the Veterans Administration Hospital in Ann Arbor, Michigan. Mean age of the subjects was 59 years. One was less than 20 years old, five over 70 years, and nine were females. The details about tissue storage are given in an earlier paper by the authors (Mohan and Melvin, 1982).

When the equipment was ready for testing the aorta was slit open and cleaned leaving the intima and adventitia intact. Circular specimens of $6.5 \mathrm{~cm}$ or $5.0 \mathrm{~cm}$ diameter (depending on the artery size) were cut out from the aorta wall and the axial direction of the aorta marked on the specimen. Then a rubber O-ring of $5 \mathrm{~cm}$ diameter or $4 \mathrm{~cm}$ diameter was bonded on to the specimen using a special locating plate shown in Fig. 1. This was done by placing the O-ring on the circular center boss, applying Eastman 910 adhesive to the top surface and then placing the specimen on top of it. A circular grid was imprinted on the specimen with a rubber stamp centered on the locating plate. The thickness of the specimen was measured with an Ames $5642-1$ thickness gage (smallest division $0.025 \mathrm{~mm}$ ) at several places on the specimen and the average value was recorded.

An assembly drawing of the essential features of the bubble inflation apparatus is shown in Fig. 2, a photograph of the apparatus in Fig. 3. The O-ring with the specimen was placed on this apparatus with a thin, highly extensible, rubber membrane (from a condom) below it. This was done to prevent air from escaping through the holes in the aortic specimen. The specimen and $\mathrm{O}$-ring were clamped in place by a top sealing ring which, along with the O-ring so clamped the tissue specimen that extreme stress concentrations would not occur along the clamping region. The device was connected to an air chamber with a quick-opening

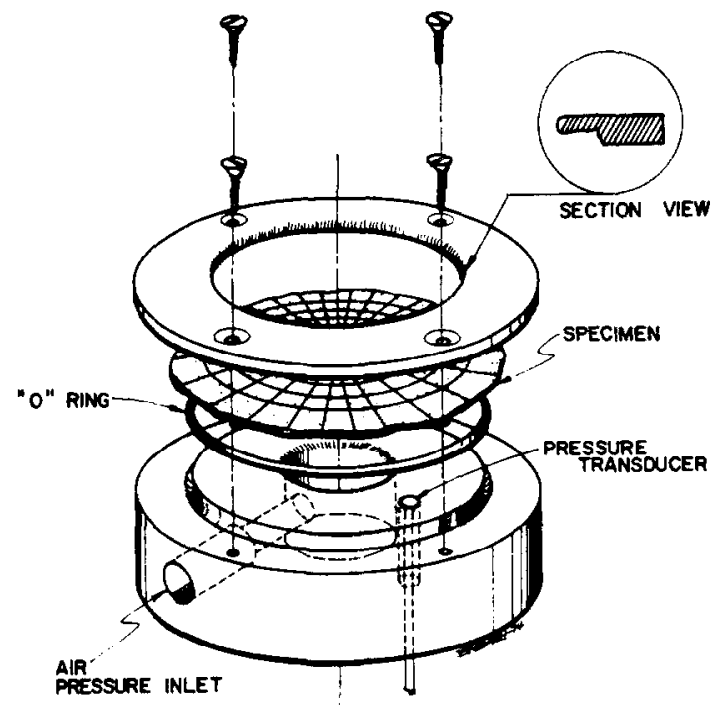

Fig. 2. Assembly drawing showing the essential features of the bubble inflation apparatus. The section view in the inset shows the cross-section of the clamping plate which was specially designed such that the soft tissue would not get out during clamping. A rubber $O$ ring was used to ensure air-tight clamping of the tissue.

solenoid valve for inflation. In the initial tests there were two front surface mirrors placed orthogonally at an inclination of $45^{\circ}$ to the tissue surface. In all the other tests there were four mirrors. In this manner the three-dimensional deformations could be recorded by one camera mounted overhead. Before the actual test, the specimen was 'preconditioned' by manually infiating and deflating the specimen. This was done four or five times. The extent of inflation could not be standardized owing to the wide variability in the specimen quality. The amount that the specimen was inflated depended on the judgement of the investigator and no specimens were tested in which any visual failure occurred in this phase of preconditioning.

\section{Testing methods}

Quasi-static tests. In these tests the specimen was inflated by controlling the entry of pressurized air with a hand operated valve such that time to failure was about $40-80 \mathrm{~s}$. The pressure was measured by a National Semiconductor LX1730G gage pressure transducer with a signal conditioner and the output was recorded on a Brush strip-chart recorder. The deformation history was recorded by taking photographs with a $35 \mathrm{~mm}$ Honeywell Pentax camera. A photodiode was mounted facing the camera strobe, and every time a picture was taken the flash would produce a voltage spike from the photodiode circuit, which was recorded along with the pressure-time trace. The photographs and pressure-time history were synchronized with the help of these timing marks. Al! tests were run until rupture of the tissue. Figure 4 shows the experimental set up. 


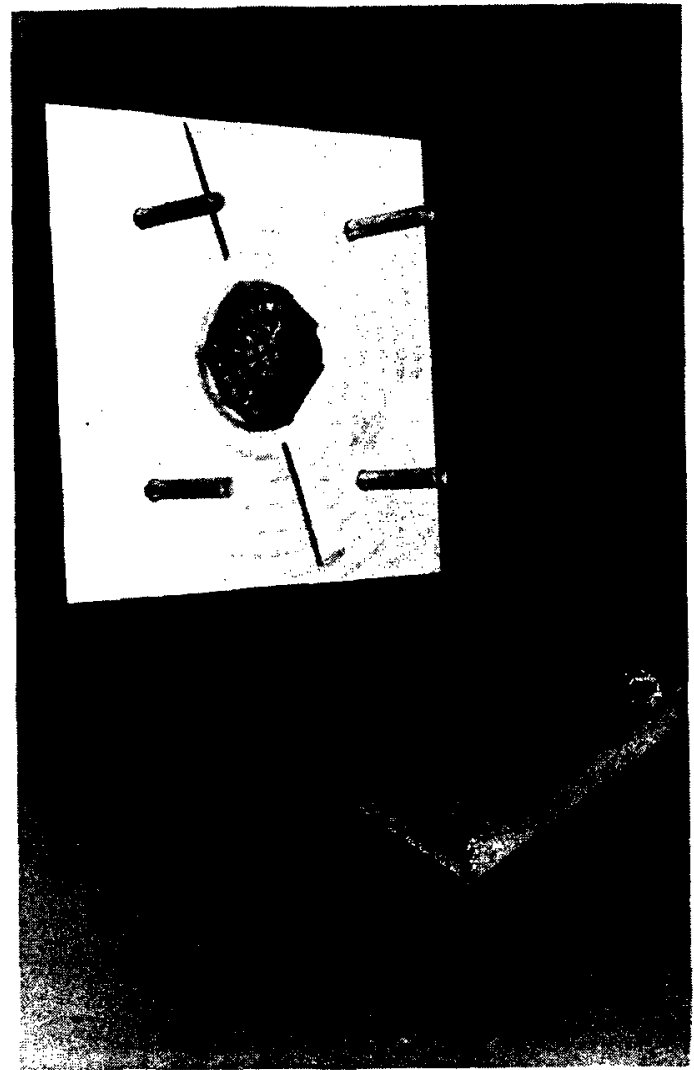

Fig. 1. Stamp pad and locating plate for biaxial test specimens. The circular specimen was placed such that the direction of the longitudinal axis of the aorta would fall along one diameter of the stamped grid. 


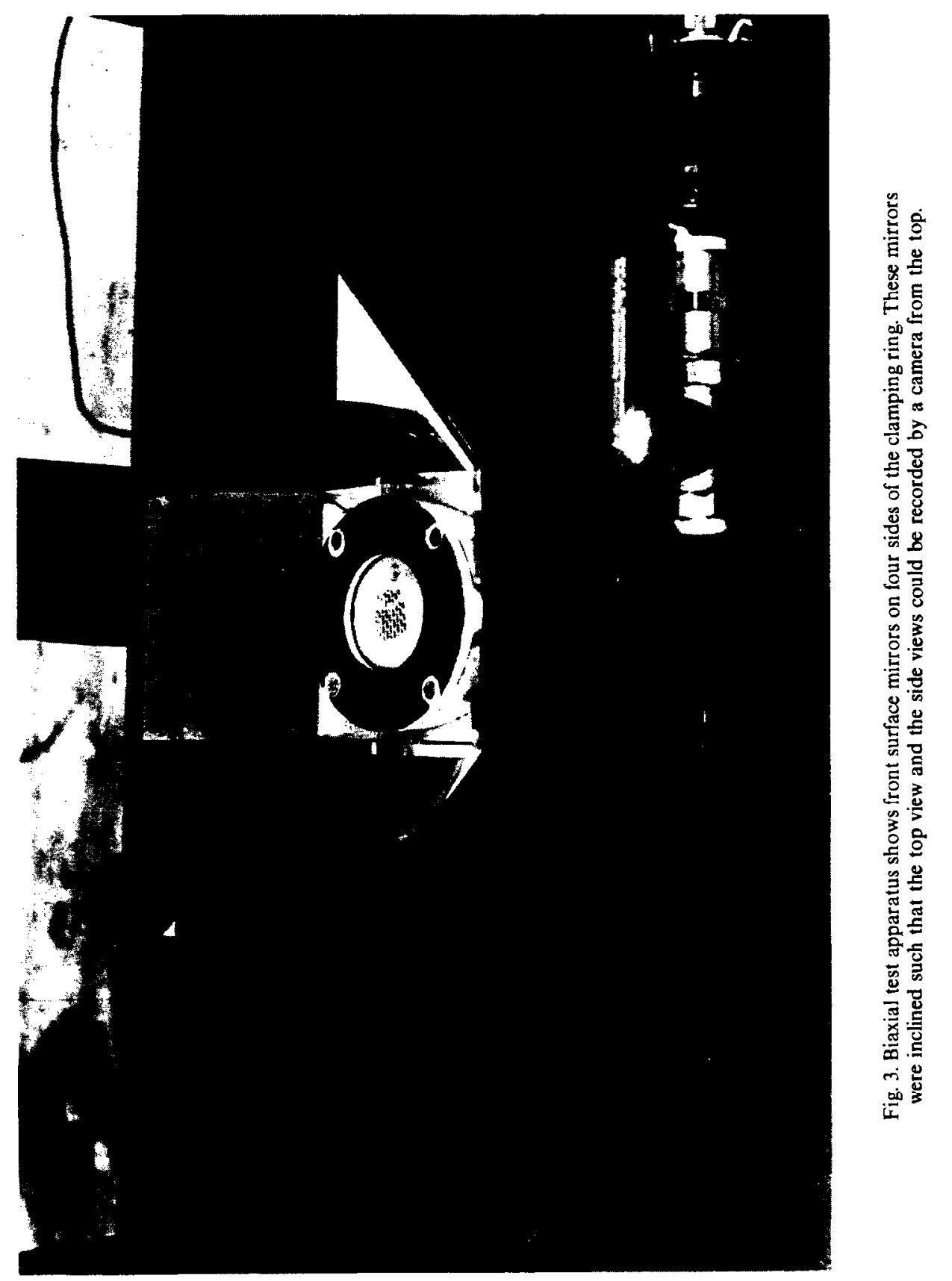




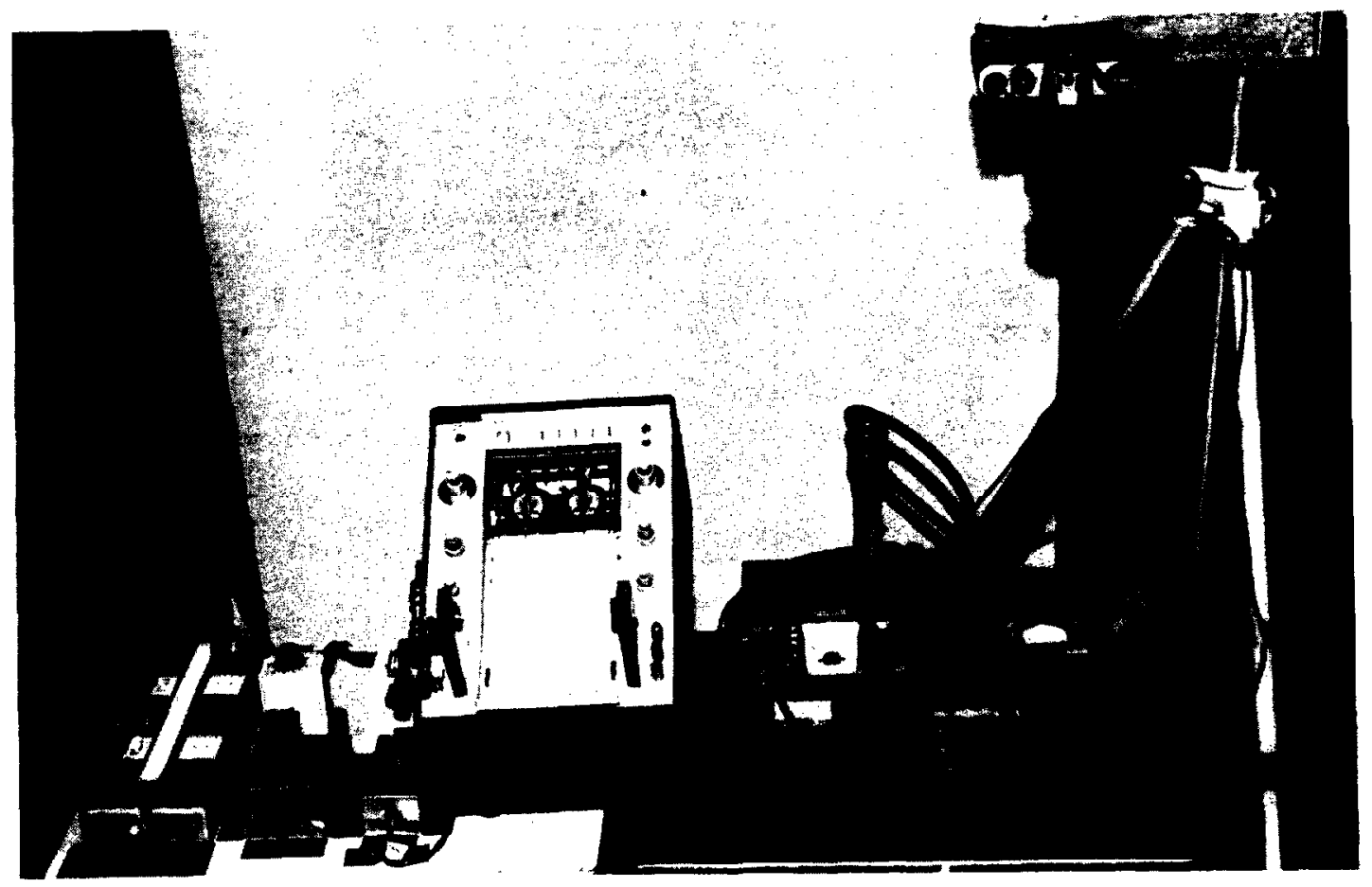

Fig. 4. Set-up for the quasi-static biaxial tests. In these the extension histories were recorded by a $35 \mathrm{~mm}$ Pentax still camera and load-time histories on a Brush recorder. 


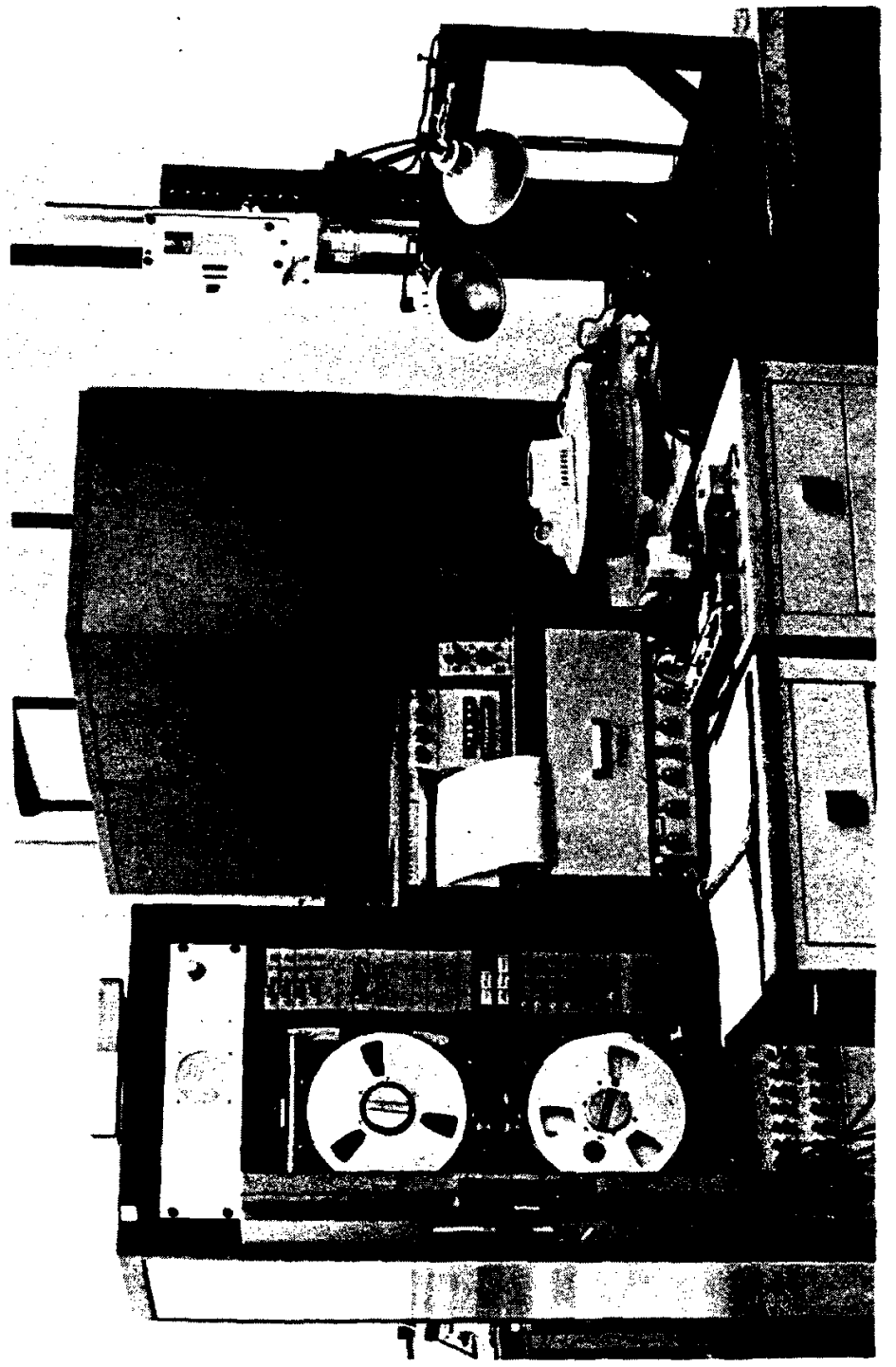

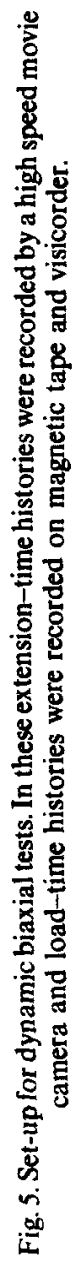



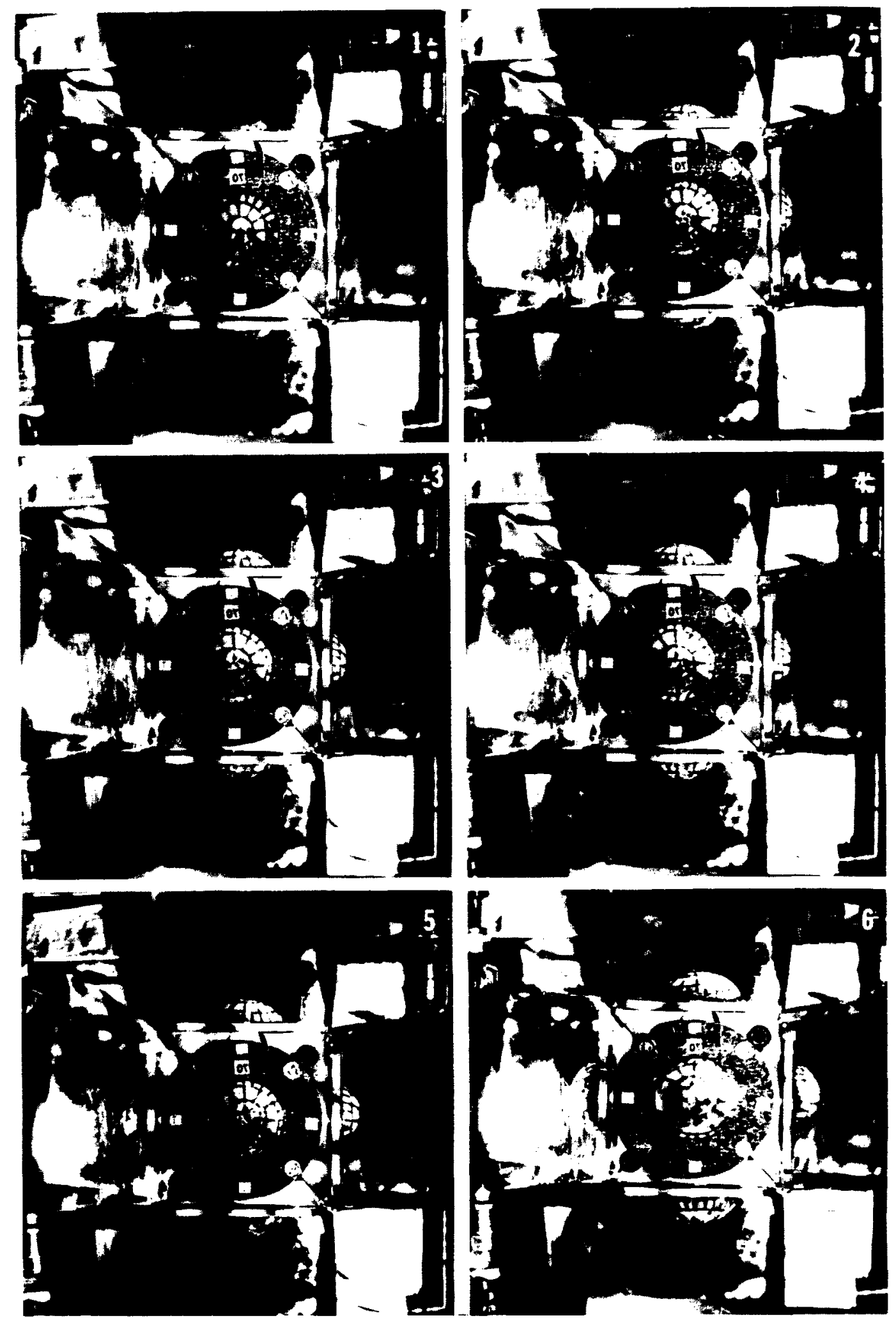

Fig. 7. Photographic record for the biaxial test. This shows six successive frames as the tissue is inflated. The four side views and top views are recorded in each frame. 
Dynamic tests. In these tests the air chamber was charged with air compressed to between 6.9 and $9.7 \times$ $10^{5} \mathrm{~N} / \mathrm{m}^{2}$. When the quick-opening solenoid valve was actuated the specimen was inflated very rapidly to failure. This procedure gave a nominal strain rate of $20 \mathrm{~cm} /(\mathrm{cm} \cdot \mathrm{s})$. The pressure was measured by a Kistler piezoelectric pressure transducer and Kistler charge amplifier and the output recorded on an Ampex CP 100 tape recorder. The deformation was photographed by a Photosonic $1 \mathrm{~B}$ movie camera using film speeds of $1000 \mathrm{frames} / \mathrm{s}$. The film record was correlated with the load-time trace by an initial single flash light and simultaneous recording of time pulse generator timing marks $\left(1000 \mathrm{~s}^{-1}\right)$ on the film and pressure-time trace. Fig. 5 shows the experimental set-up.

Data reduction. The circular sheet of aortic tissue was fixed at its outside edge and when pressure was applied from one side the sheet deformed into a surface of revolution. For the purposes of this analysis aortic tissue was assumed to be incompressible, homogeneous and nominally isotropic. For such materials the deformation is expected to be maximum near the pole of the inflated bubble (Joye et al., 1972) and the surface spherical in shape. Based on the available theory, the following procedure was used to establish the stress and extension ratio relationships for the biaxial tests.

1. The photographic records of the test were enlarged and printed on photographic paper or projected and traced out on paper.

2. From each record the diameter of the innermost circle was measured in two directions, transverse and longitudinal to the axis of the aorta, and their mean recorded (Fig. 6).

3. The circumferential curvature $R$ for the portion enclosed by the innermost circle was obtained by drawing tangents to the profile of the deformed membrane. From the points of contact, normals were drawn and the distance from the point of intersection of the normals to the tangent gave the radius of curvature $R$ of the deformed profile. This was done for each of the good views and a mean $R$ obtained (Fig. 6).

Measured variables.

1. Inflation pressure, $P$.

2. Initial diameter of innermost circle, $d_{0}$.

3. Current diameter of innermost circle, $d$.

4. Current radius of curvature of deformed membrane, $R$.

5. Initial membrane thickness, $h_{0}$.

Calculated variables. The following assumptions
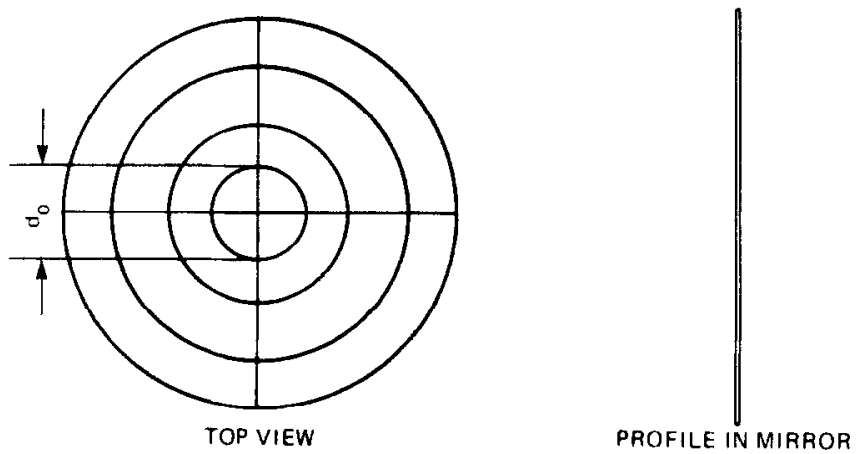

BEFORE PRESSURIZATION

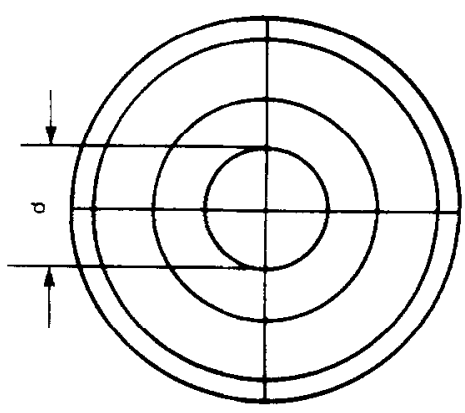

CONSTRUCTION LINES

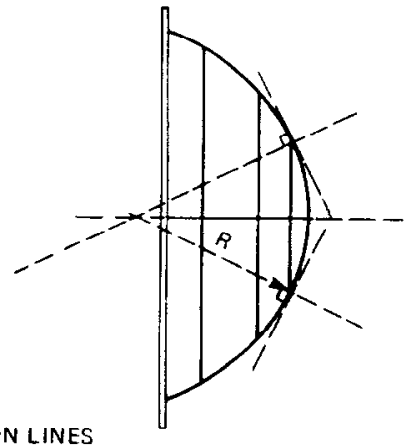

TOP VIEW

DEFORMED PROFILE IN MIRROR 
Table 1. Ultimate stress and extension ratio values

\begin{tabular}{|c|c|c|c|c|c|c|}
\hline \multirow[b]{2}{*}{$\begin{array}{l}\text { Spec } \\
\text { No. }\end{array}$} & \multirow[b]{2}{*}{$\begin{array}{l}\text { Age } \\
\text { Years }\end{array}$} & \multirow[b]{2}{*}{ Sex } & \multicolumn{2}{|c|}{ Quasi-Static } & \multicolumn{2}{|c|}{ Dynamic $\left(\sim 20 \sec ^{-1}\right)$} \\
\hline & & & $\begin{array}{l}\text { True Stress } \\
\sigma_{\text {wlt }} \\
\left\{\mathrm{N} / \mathrm{m}^{2} \times 10^{4}\right\}\end{array}$ & $\begin{array}{c}\text { Extension Ratio } \\
\lambda \\
\mathrm{cm} / \mathrm{cm}\end{array}$ & $\begin{array}{l}\text { True Stress } \\
0_{\text {ult }} \\
\left(\mathrm{N} / \mathrm{m}^{2} \times 10^{4}\right)\end{array}$ & $\begin{array}{c}\text { Extension Ratio } \\
\lambda \\
\mathrm{cm} / \mathrm{cm}\end{array}$ \\
\hline 8 & 79 & M & $\cdots$ & $\cdots$ & 192 & 1.25 \\
\hline 9 & 49 & $\mathbf{F}$ & $\cdots$ & -.-- & .... & $1.48^{*}$ \\
\hline 10 & 71 & M & $\cdots-$ & $\cdots$ & 126 & 1.24 \\
\hline 17 & 89 & $\mathbf{F}$ & $\cdots$ & $\cdots$ & 144 & 1.15 \\
\hline 19 & 87 & M & -.-- & $\cdots$ & 218 & 1.35 \\
\hline 20 & 62 & $F$ & $\cdots$ & $\ldots$ & 226 & 1.24 \\
\hline 22 & 10 & $\mathbf{M}$ & -... & $\ldots$ & $84^{*}$ & $1.02^{*}$ \\
\hline 24 & 79 & $\mathbf{F}$ & -.-- & $\cdots$ & 188 & 1.01 \\
\hline 27 & 54 & $\mathrm{~F}$ & $\cdots$ & $\cdots$ & 318 & 1.47 \\
\hline 28 & 57 & $F$ & $\cdots$ & $\ldots$ & $154^{*}$ & $1.28^{*}$ \\
\hline 29 & 53 & $M$ & 148 & 1.58 & $13.9 t$ & $\cdots$ \\
\hline 30 & 49 & $\mathrm{~F}$ & 148 & 1.04 & 225 & $1.49^{*}$ \\
\hline 31 & 60 & M & 86 & 1.32 & 220 & 1.03 \\
\hline 32 & 53 & $F$ & 105 & 1.05 & $15.2 \uparrow$ & $\cdots \cdot$ \\
\hline 33 & 59 & $F$ & 82 & 1.38 & 134 & 1.38 \\
\hline 34 & 25 & $M$ & $208^{*}$ & $1.62^{*}$ & -.- & $\cdots$ \\
\hline Mean & 59 & . & 114 & 1.44 & 196 & 1.28 \\
\hline S.D. & 21 & - & 32 & 0.10 & 60 & 0.11 \\
\hline N. & 16 & - & 5 & 5 & 9 & 9 \\
\hline
\end{tabular}

have been made to calculate the variables described below: (a) the deformed membrane is spherical in the polar region; (b) extension ratios of the radial line elements are equal to those of the circumferential line elements in the polar region; (c) stresses in the radial line elements are equal to those in the circumferential line elements in the polar region; (d) aortic tissue is incompressible ; and (e) hoop stress approximation for stress is valid in the polar region (Joye et al., 1972).

1. Radial extension ratio, $\lambda_{1}=\frac{d}{d_{0}}$.

2. Circumferential extension ratio, $\lambda_{2}=\frac{\pi d}{\pi d_{0}}=\frac{d}{d_{0}}$

3. Thickness extension ratio,

$$
\lambda_{3}=h / h_{0}=\frac{1}{\lambda_{0} \lambda_{2}}=\frac{1}{\lambda^{2}}
$$

$\left\{\begin{array}{l}\text { Incompressibility condition, } \lambda_{1} \cdot \lambda_{2} \cdot \lambda_{3}=1 \\ \text { but } \lambda_{1}=\lambda_{2}=\lambda=d / d_{0}, \\ \text { therefore } \lambda^{2} \cdot \lambda_{3}=1\end{array}\right.$

4. Engineering tensile stress (Hoope stress), $\sigma_{E}=P R / 2 h_{0}$

5. True tensile stress, $\sigma_{T}=P R / 2 h=P R / 2 \lambda_{3} h_{0}$

$$
=P R \lambda^{2} / 2 h_{0}=\sigma_{E} \cdot \lambda^{2} \text {. }
$$

\section{Sources of errors}

In the biaxial tests a latex rubber condom diaphragm of thickness $0.094 \mathrm{~mm}$ was placed under the aortic tissue. This was done to prevent pressurized air from escaping through the holes in the tissue. When the rubber diaphragm was inflated in the absence of the aortic tissue it assumed large spherical shapes at pressures lower than $1.0 \mathrm{psi}$. Since the aortic tissue was more than 20 times thicker than the diaphragm, much less distensible and much stiffer, it has been assumed 
that the rubber diaphragm did not influence aortic behavior and acted as a sealant only. The radius of curvature of the deformed membrane was determined using a graphical method and the value thus obtained was subject to measurement and approximation errors. In each case that value was checked roughly by placing circle templates of different diameters over the arc. The graphical method was used to measure the radii of curvature on arcs of known curvature and the values were found to be within $2 \%$ of the correct value every time. Due to imperfections of photography, not all side images were always useful. For each frame, the average radius of curvature was calculated from the useable side views. In each frame, the smallest radius was within $15 \%$ of the largest value in almost all cases and only rarely did this difference go up to $25^{\circ} \%$ However, by using mean values, the error was expected to remain within $10 \%$. The measurements were calibrated by using the diameter of the clamping ring of the apparatus as the standard measurement. As a result the errors due to enlargement were kept to a minimum.

Since the radius of curvature is needed for calculating stress. any errors in the former would be transferred to the latter. This is the shortcoming of this analysis and because extension ratios are calculated from direct measurements and stress values calculated indirectly, the former values will be more accurate than the latter. Different formulae have been used to calculate stresses
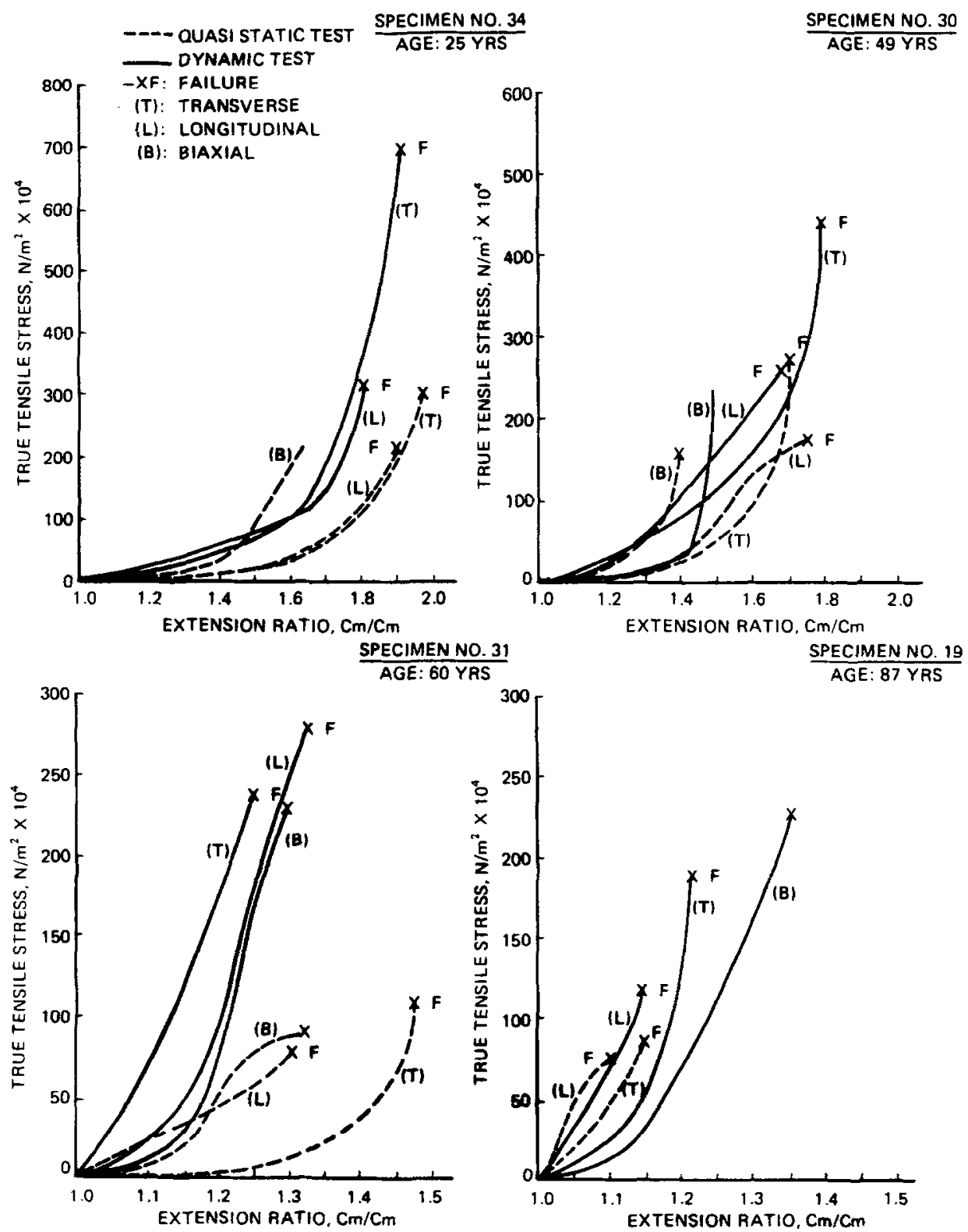

Fig. 8. True stress versus extension ratio curves for human aortas. Data for uniaxial tests have also been included. 
in inflated membranes in bubble inflation tests. According to the data presented by Joye et al. (1972) the formula used in this study is most accurate for the region near the pole and the results are almost identical with those arrived at by using a more complicated and accurate method. Therefore, the formula used here was considered adequate for the purposes of this study.

\section{RESULTS}

The ultimate stress and extension-ratio values of the specimens tested are shown in Table 1. An example of the sequence of photographs taken during a test is given in Fig. 7 and examples of stress versus extensionratio curves are given in Fig. 8. When looking at the numbers included in Table 1 the following points should be kept in mind.

1. Invalid tests are those where the specimen failed near the grips or slipped out. The maximum stress and extension-ratio values in these cases are not true ultimate values and have not been included in any analysis.

2. Dynamic tests had nominal strain rate values of $20 \mathrm{~cm} /(\mathrm{cm} \cdot \mathrm{s})$ and quasi static tests $0.01 \mathrm{~cm} / \mathrm{cm} \cdot \mathrm{s})$.

3. The ultimate extension-ratio values are means of extension ratios in the longitudinal and transverse directions. The ultimate extension ratio in one direction was always within $7 \%$ of the value in the direction perpendicular to it. There was no discernable pattern in the distribution of the ratios by direction.

4. Failure of the aortic tissue always took place with a tear in a direction perpendicular to the longitudinal axis of the aorta.

\section{Statistical analysis of the failure properties}

Failure properties were compared according to the following test pairs.
1. Biaxial dynamic tests versus uniaxial dynamic longitudinal tests. The data for the uniaxial tests is given in an earlier publication by the same authors (Mohan and Melvin, 1982).

2. Biaxial quasi-static versus uniaxial quasi-static longitudinal tests.

3. Biaxial quasi-static versus biaxial dynamic tests. Only pressures at failure were compared, as enough pairs could not be obtained to compare stresses and extension ratios.

Failure properties in the biaxial mode were compared with failure properties in the longitudinal uniaxial mode since in all tests the initial tear occurred in the transverse direction. That is, the failure was due to stretching in the longitudinal direction. For each comparison, only those tests were chosen which could be paired by specimen source. The ratios between paired values were calculated and these ratios were used to test the hypothesis that the mean of the ratios was equal to unity. The Students' $t$ statistic was used to test the hypothesis for a level of significance equal to 0.01 and the results were the same for a level of significance of 0.05 . If the null hypothesis was rejected, it meant that there was no provable difference between the two groups. The results of this analysis are given in Table 2. Since not enough pairs were available to compare stress or extension ratio values for biaxial tests, the failure pressures were compared to evaluate the effect of strain rate. As indicated in the table, the failure pressures in dynamic biaxial tests were significantly greater than the failure pressures in the quasistatic tests by a mean factor 2.14 . Since all tests were paired by source there were no significant differences in tissue thicknesses within each pair. It may be assumed that the ratio between ultimate stresses would be similar to that between ultimate pressures since the ultimate extension ratios were similar in the quasistatic and dynamic tests.

Table 2. Statistical comparison of failure properties

\begin{tabular}{|c|c|c|c|c|c|c|}
\hline Parameter Description & $\begin{array}{c}\text { Mean } \\
\text { of } \\
\text { Ratios }\end{array}$ & $\begin{array}{l}\text { Estimated } \\
\text { Standard } \\
\text { Deviation }\end{array}$ & $\begin{array}{c}\text { Number } \\
\text { of Pairs } \\
\mathrm{N}\end{array}$ & $\stackrel{t}{\text { Statistic }}$ & $\stackrel{t_{0.01}}{N-1}$ & $\begin{array}{c}\text { Null } \\
\text { Hypothesis } \\
\text { Rejected? }\end{array}$ \\
\hline$\frac{\text { Ult. Pressure, Static }}{\text { Ult. Pressure, Dynamic }}$ & 0.4677 & 0.0565 & 4 & 18.84 & 5.841 & YES \\
\hline $\begin{array}{l}\text { Quasi-Static } \\
\text { Ult. Stress, Biaxial } \\
\text { Ult. Stress, Uniaxial }\end{array}$ & 0.8924 & 0.2607 & 5 & 0.9255 & 4.604 & No \\
\hline$\frac{\text { Uit. Ext. Ratio, Biaxial }}{\text { Ult. Ext. Ratio. Uniaxial }}$ & 0.9738 & 0.1208 & 5 & 0.4842 & 4.604 & NO \\
\hline Dynamic & & & & & & \\
\hline$\frac{\text { Ult. Stress, Biaxial }}{\text { Ult. Stress, Uniaxial }}$ & 1.11 & 0.3730 & 4 & 0.5898 & 5.841 & NO \\
\hline$\frac{\text { Ult. Ext. Ratio, Biaxial }}{\text { Ult. Ext. Ratio, Uniaxial }}$ & 0.9647 & 0.1843 & 4 & 0.3830 & 5.841 & NO \\
\hline
\end{tabular}


The comparison of biaxial test results with longitudinal uniaxial test results shows that no significant differences can be demonstrated between the two sets. Though the ultimate stress values in the biaxial and uniaxial tests are very similar, we would like to point out that these results are based on comparing four or five pairs only.

\section{DISCUSSION}

There is no data available which can be compared directly with the test results reported here since all the other biaxial experiments were done on tubular specimens of the aorta with the intention of obtaining pressure-volume curves and then calculating stresses. Tanaka and Fung (1974) have mentioned the need for determination of biaxial properties of the aortic tissue in their paper on properties of canine aorta. Lee $e t$ al. (1967) had earlier tested dogs' carotid arteries in the cylindrical form in large deformation, but their data cannot be compared since the carotid artery is structurally different from the aorta. Yamada (1970) has tabulated expansive properties (bubble inflation test) of human arteries and rupture properties (expansion of the tubular vessel) of animal aortas, and Hildebrandt et al. (1969) performed bubble inflation tests on dog pericardium and cat mesentary. True stresses were not evaluated in Yamada's data so only approximate calculations can be made.

The bubble inflation technique has been used successfully for determining viscoelastic properties of rubber, plastic, and other polymeric materials by many researchers (Joye et al.. 1972, 1973; Dong, 1974; Schmidt and Carley, 1975). As mentioned earlier, the extension ratios were calculated directly by measuring the diameters of the innermost circle which is expected to be the region of highest stress. Almost all the failures took place around this region so this assumption was justified. The extension ratios in the longitudinal (axial direction of the vessel) and transverse directions were found to be within $5^{\circ},{ }_{0}$ of the larger value. The ultimate extension ratio was not consistently greater in any one direction, hence means were taken of the two values. The differences were greater when the stresses were low but hardly detectable when the stresses and strains were high. The true stresses were more difficult to evaluate and subject to greater errors. Since the stresses were calculated indirectly, accuracy of the stress values is more questionable than that of the strain values. As Hildebrandt et al. (1969) and Joye et al. (1972) have pointed out, because of the approximations the true stresses calculated would tend to be on the lower side. Another source of error in calculating true stresses could arise from the assumption concerning the incompressibility of aortic tissue. All evidence from other studies on soft tissues indicates that this is a reasonable assumption.

The results may be summarized as follows:

1. Under a state of uniform biaxial stretch, the aortic tissue always failed with the initial tear in the transverse direction.

2. The ultimate stresses and extension ratios of the quasi-static and dynamic tests were similar to those of the uniaxial longitudinal tests and no significant differences could be detected.

3. The mean failure pressure in the dynamic tests was 2.14 times greater than that in the quasi-static tests. This difference was significant at the $99 \%$ level. The confidence limits for this ratio are 1.58-2.7.

The ultimate true stresses at the quasi-static and dynamic strain rates could not be compared by pairing since movie records of a few relevant samples were lost in the experiments and the extension ratios and stresses could not be calculated. Since all comparisons were paired by source, there were no significant differences in tissue thickness within each pair. And since the values of ultimate extension ratios do not seem to be influenced by strain rate in the uniaxial tests; it may be hypothesized that the same may be true in the biaxial tests (Mohan and Melvin, 1982). Therefore, in the biaxial test3, the ratio of ultimate stresses in the quasi-static and dynamic tests would be similar to the ratio of ultimate pressures. This would indicate that the effect of strain rate on ultimate stresses of biaxial specimens is similar to that recorded in uniaxial tension tests on aortic tissue (Mohan and Melvin, 1982) because the ultimate pressures are greater in the dynamic tests by a factor of two than in the quasi-static tests. Though there was no statistical differences between the ultimate stresses of dynamic biaxial tests and dynamic uniaxial longitudinal tests. some curves do show slightly lower stresses for the biaxial tests. Perhaps the true stresses in the biaxial tests were under-estimated. Also, these tests were performed at strain rates of $20 \mathrm{~s}^{-1}$ while the uniaxial tests had a nominal rate of $100 \mathrm{~s}^{-1}$.

Yamada's mean value for ultimate expansion strength of human thoracic aorta at quasi-static strain rates was $74 \mathrm{~N} / \mathrm{m}^{2}$. This is an engineering stress value and the experimental technique used was different. The mean value for true stress (greater than engineering stress) calculated in the quasi-static tests reported above is $114 \mathrm{~N} / \mathrm{m}^{2}$. Considering the differences in technique, these two values are quite similar.

In the uniaxial dynamic tests, differences of behavior were noted between the longitudinal and transverse specimens, whereas in the biaxial tests, the extension ratios in the two directions were very similar at higher stresses. This apparent difference can be explained by examining the curves of the uniaxial tests a little more closely. It is noticed that in the high stress regions the behavior of longitudinal and transverse specimens in uniaxial tests is very similar. Though the longitudinal specimens fail at lower stresses than transverse specimens, owing to the high stiffness the difference in extension ratio at that stress level becomes very small. Since the stresses may tend to be distributed and equalized in the biaxial test (the difference in extension ratios in the two directions in the uniaxial tests was 
typically $0.05 \mathrm{~cm} / \mathrm{cm}$ ), the difference in extension ratios in the two directions would not be discernable in the biaxial tests.

In our estimation, the most important finding from the biaxial tests is that the aortic tissue always fails in a transverse direction when stretched uniformly and that the stress and strain levels are similar to those in uniaxial tests. These findings have important significance in predicting theories of failure. The uniaxial stretch experiments indicated that it is possible for a transverse failure to be caused by high pressure alone and that the most reasonable failure theory for aortic tissue is the maximum tensile strain theory. The biaxial test results when considered in conjunction with the uniaxial tests. These findings have important significance in predicting theories of failure. The uniaxial

\section{SUMMARY}

This is the first time that the passive mechanical properties of the human descending aorta have been evaluated in the biaxial mode at strain rates as high as $20 \mathrm{~s}^{-1}$. The bubble inflation method was found very suitable for doing biaxial tests on soft tissues. The major conclusions are:

1. Under conditions of uniform biaxial stretch the aortic tissue consistently fails in the transverse direction.

2. The dynamic failure pressures were significantly greater (by a factor of two) than quasi-static failure pressures.

3. Biaxial test results when considered in conjunction with uniaxial tension test results support the theory that it is possible for the aorta to fail with a tear perpendicular to axis due to high pressure alone.

Acknowledgements-Part of this work was supported by NHTSA Contract No. DOT-HS-031-3-763 and NSF Grant No. ENG 75-04267.

\section{REFERENCES}

Cammack, K., Rapoport, R. L., Paul, J. and Baird, W. C. (1959) Deceleration injuries of the thoracic aorta. Archs Surg. 79, 244-251.

Cheung, J. B. and Hsiao, C. C. (1972) Non-linear anisotropic viscoelastic stresses in blood vessels. J. Biomechanics 5, 607-619.

Collins, R. and Hu, W. C. L. (1972) Dynamic deformation experiments on aortic tissue. J. Biomechanics 5, 333-335.

Dong, R. G. (1974) Tensile failure of viscoelastic materials under multiaxial loading at various temperatures. Trans. Soc. Rheol. 18, 45-63.

Hildebrandt, J., Fukdya, H. and Martin, C. J. (1969) Stress-strain relations of tissue sheets undergoing uniform two-dimensional stretch. J. appl. Physiol. 27, 758-762.
Joye, D. G., Poehlein, G. W. and Denson, C. D. (1972) A bubble inflation technique for the measurement of viscoelastic properties in equal biaxial extension flow I, Trans. Soc. Rheol. 16, 421-445.

Joye, D. D., Poehlein, G. W. and Denson, C. D. (1973) A bubble inflation technique for the measurement of viscoelastic properties in equal biaxial extensional flow II. Trans. Soc. Rheol. 17, 287-302.

Kivity, Y. and Collins, R. (1974) Non-linear wave propogation in viscoelastic tubes: application to aortic rupture. J. Biomechanics 7, 67-76.

Kroell, C. K., Schneider, D. C., and Nahum. A. M. (1974) Impact tolerance and response of the human thorax II. Proceedings of the Eighteenth Stapp Car Crash Conference. Society of Automotive Engineers, Warrendale, PA.

Lee, J. S., Frasher, W. G. and Fung, Y. C. B. (1967) Twodimensional finite deformation experiments on dog's arteries and veins. Report No. AFOSR 67-1980, Air Force Office of Scientific Research, Arlington, VA.

Letterer, E. (1924) Beitrage zur Entstehung der Aorterupter an typischer stelle, Virchows Arch. path. Anat. Physiol. 253, 534-544.

Lundewall, J. (1964) The mechanics of traumatic rupture of the aorta. Acta pathol. microbiol. scand. 62, 34-36.

Mohan, D. and Melvin, J. W. (1982) Failure properties of passive human aortic tissue. I-uniaxial tension tests. $J$. Biomechanics 15, 887-902.

Oppenheim, F. (1918) Gibt es eine Spontanruptur der gesunden Aorta and wie kommt es zustande, Munch med. Wschr. 65, 1234-1237.

Ray, G., Liu, Y. K. and Davids, N. (1975) Wall stress in curved aorta in blunt chest trauma, Proceedings of the 28th Annual Conference on Engineering in Medicine and Biology. Alliance for Engineering in Medicine and Biology, Chevy Chase, MD.

Rindfleisch, E. (1873) Zur Entstehung und heilung des Aneurysma Dissecans Aortae. Virchows Arch. path. Anat. Physiol. 131, 374.

Roberts, V. L., Jackson, F. L. and Berkas, E. M. (1967) Heart Motion Due to Blunt Trauma to the Thorax, Proceedings of the Tenth Stapp Car Crash Conference. Society of Automative Engineers, Warrendale, PA.

Roy, C. S. (1880) Elastic properties of arterial wall. J. Physiol., Lond. 3, 125-159.

Schmidt, L. R. and Carley, J. W. (1975) Biaxial stretching of heart softened plastic sheets using an inflation technique. Int. J. engng Sci. 13, 563-578.

Shatsky, S., Alter, W. A., Evans, D. E., Armbrustmacher, V. and Clarke, G. (1974) Traumatic distortions of primate head and chest : correlations of biomechanical, radiological and pathological data. Proceedings of the Eighteenth Stapp Car Crash Conference. Society of Automotive Engineers, Warrendale, PA

Sheman, T. (1929) Traumatic (false) aneurisms of the aorta. J. Path. Bact. 32, 795-798.

Tanaka, T. T. and Fung, Y. C. (1974) Elastic and inelastic properties of the canine aorta and their variation along the aortic tree. J. Biomechanics 7, 357-370.

Tannenbaum, I. and Ferguson, J. A. (1948) Rapid deceleration and rupture of the aorta. Archs Path. 45, 503-506.

Yamada, H. (1970) Strength of Biological Materials (Edited by Gaynor Evans). Williams and Wilkins, Baltimore. 